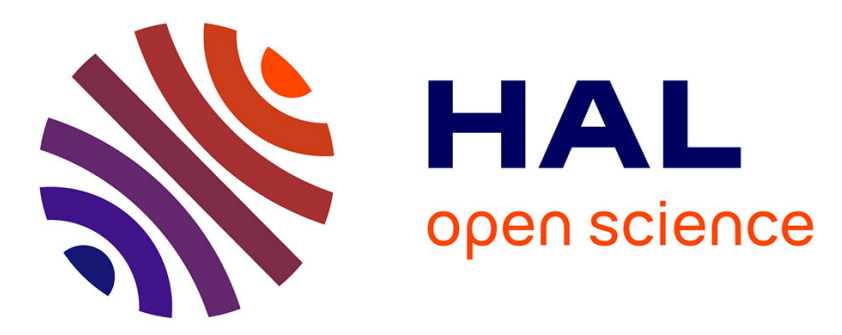

\title{
Effect of gender, carrying and planting the pole on approach step parameters in young pole vaulters
}

\author{
Johan Cassirame, Hervé Sanchez, Sébastien Homo, Julien Frère
}

\section{To cite this version:}

Johan Cassirame, Hervé Sanchez, Sébastien Homo, Julien Frère. Effect of gender, carrying and planting the pole on approach step parameters in young pole vaulters. Movement \& Sport Sciences - Science \& Motricité, 2022, 115, pp.15-23. 10.1051/sm/2021019 . hal-03524533

\section{HAL Id: hal-03524533 \\ https://hal.science/hal-03524533}

Submitted on 13 Jan 2022

HAL is a multi-disciplinary open access archive for the deposit and dissemination of scientific research documents, whether they are published or not. The documents may come from teaching and research institutions in France or abroad, or from public or private research centers.
L'archive ouverte pluridisciplinaire HAL, est destinée au dépôt et à la diffusion de documents scientifiques de niveau recherche, publiés ou non, émanant des établissements d'enseignement et de recherche français ou étrangers, des laboratoires publics ou privés. 


\title{
Effect of gender, carrying and planting the pole on approach step parameters in young pole vaulters
}

\author{
Johan Cassirame $^{1,2,3,4,{ }^{*}}$ (D) Hervé Sanchez ${ }^{3,4}$, Sébastien Homo ${ }^{3}$, and Julien Frère ${ }^{5,6}$ \\ 1 EA 4660, Culture, Sport, Health and Society Department and Exercise Performance, Health, innovation platform, University \\ of Bourgogne-France-Comté, Besançon, France \\ 2 EA 7507, Laboratoire Performance, Santé, Métrologie, Société, Reims, France \\ ${ }^{3}$ French Athletics Federation (FFA), FIR division, Paris, France \\ 4 Mtraining, R\&D division, École Valentin, France \\ ${ }^{5}$ Univ. Grenoble Alpes, CNRS, Grenoble INP, GIPSA-Lab, 38000 Grenoble, France \\ ${ }^{6}$ Université de Lorraine, DevAH, F-54000 Nancy, France
}

Received 12 May 2020, Accepted 6 October 2021

\begin{abstract}
In pole vaulting, take-off speed is considered as a major determinant of performance. Pole carriage could affect the speed acquired during the approach and at the take-off. This study investigated different types of runs performed randomly by young male and female expert athletes: maximal sprint, maximal pole carriage run, maximal run-up with simulated pole plant and competition situation. Speed profile was determined with a radar gun and spatiotemporal parameters were recorded for the last $20 \mathrm{~m}$ of the approach with the Optojump Next system. For both genders, mechanical variables were compared using two-way ANOVAs with repeated measurements. Pole carriage represents the main cause of speed decrease for both men $(-5.8 \%)$ and women $(-6.2 \%)$. A step rate decrease during pole carriage was pointed out with an increase of contact time for both men and women. Significant speed decrease was observed for women at the take-off compared to pole plant simulation $(-4.3 \%)$, while not for men. Those results provide a new insight for pole vault training allowing to update training process with specific exercises leading to reduce speed loss at take-off.
\end{abstract}

Keywords: pole vault, sprint, training, speed, optimisation

Résumé - Impact du genre, port de perche et du présenté sur la vitesse d'élan chez des jeunes sauteurs à la perche. En saut à la perche, la vitesse au décollage est un déterminant majeur de la performance. Pendant la course, le port de perche affecte directement la vitesse utilisable au décollage. Cette étude analyse de manière randomisée l'impact du port de la perche, du présenté et du décollage complet en compétition sur la vitesse maximale atteinte par l'athlète. La vitesse de course et les paramètres spatio-temporels de la course sont collectés dans chaque situation de course via un radar et $20 \mathrm{~m}$ de système Optojump Next. Pour chaque sexe, chaque condition a été comparé en utilisant une ANOVA à 2 facteurs à mesures répétées. Le port de perche induit une diminution de la vitesse pour les hommes $(-5.8 \%)$ et $(-6.2 \%)$ pour les femmes. Une diminution de la cadence est associée à une augmentation du temps de contact aussi bien chez les hommes que chez les femmes. Une diminution significative de la vitesse a été observée chez les femmes uniquement entre le présenté simulé et un décollage réel en compétition $(-4.3 \%)$. Ces résultats permettent un nouveau regard pour l'entraînement de la phase d'élan et une priorisation sur des stratégies visant à réduire la perte de vitesse spécifiquement chez les femmes.

Mots clés : saut à la perche, sprint, entraînement, vitesse, optimisation

\footnotetext{
*Corresponding author: johancassirame@free.fr
} 


\section{Introduction}

Usually, pole vault practice is described by 4 successive phases starting from run-up, take-off (including pole plant), pole bending and pole straightening including pole release and bar clearance (Frère, L'Hermette, Slawinski, \& Tourny-Chollet, 2010). To achieve the best possible performance, athletes have to transfer the maximum of energy from their approach run to the pole and use energy recoil to elevate their centre of mass as high as possible (Arampatzis, Schade, \& Brüggemann, 2002; Linthorne \& Weetman, 2012; Schade \& Arampatzis, 2012; Schade, Arampatzis, \& Brüggemann, 2006). Several previous studies demonstrated a strong relationship between the horizontal take-off speed and performance in pole vault (Cassirame et al., 2019; Cassirame, Sanchez, Homo, \& Frère, 2017; Decker \& Bird, 2008; Linthorne \& Weetman, 2012; Steinacker, 1991). Basically, speed is growing during the run-up phase, and the related kinetic energy is then transferred into the bending pole. For this reason, take-off speed is considered as a major performance determinant and has been subjected to scrutiny from scientists during major championships (Choi et al., 2013; Schade, Arampatzis, Brüggemann, \& Komi, 2004).

Even if pole-athlete interaction is mainly investigate from take-off to bar clearance (Arampatzis et al., 2002; Ekevad \& Lundberg, 1997; Frère, Göpfert, Hug, Slawinski, \& Tourny-Chollet, 2012), only few studies have investigated the impact of pole carriage and pole plant movement before take-off. Frère et al. investigate the effect of pole carriage on novice male vaulters during run-up phase without planting the pole into the box (Frère, Chollet, \& Tourny-Chollet, 2009). They demonstrated that pole carriage induces a loss in horizontal speed $(-6.6 \%)$ mainly related to step length (SL) and rarely related to step rate (SR) reduction. In addition, contact phase $\left(\mathrm{T}_{\mathrm{c}}\right)$ was also significantly increased with concomitant reduction of hip flexion and higher braking phase. Nevertheless, the speed range observed for examined athletes in the mentioned study was importantly lower than expected speed for both male and female elite athletes (Cassirame, Sanchez, \& Morin, 2017; Schade et al., 2004). Is it well known that speed reduction process is affected by speed level (Bushnell \& Hunter, 2007; Mero, Komi, \& Gregor, 1992). In addition, Frère et al. (2009) reported an effect of pole carriage on novice who could be more affected than experimented elite vaulters. Given that sprint and muscular capabilities from women are different than men, potential differences between sex are expected (Abe et al., 2019; Perez-Gomez et al., 2008). Recently, a study investigated the mechanical proprieties of the sprint with and without pole carriage by analysing the force-velocity profile of athletes in both conditions (Frère et al., 2017). This study reported a significant power output reduction with an alteration of both horizontal force and velocity capabilities of athletes when carrying pole. A more pronounced effect was detected on force rather than velocity suggesting a more important implication of horizontal force in speed reduction. Furthermore, no study focused on speed reduction induced by pole planting preparation at the end of the approach. Pole planting preparation induces an optimisation of step regulation to take-off at the expected position (Needham, Exell, Bezodis, \& Irwin, 2017; Theodorou, Panoutsakopoulos, \& Exell, 2016). Targeting ideal position at take-off while running fast can be seen as a dual-task which potentially alters velocity at the end of the run-up. Also, during the last stance, Frère et al. (2010) reported a decrease in speed of around $2 \mathrm{~m} / \mathrm{s}$ related to the pole plant. This critical event is highly demanding for the musculoskeletal system and may lead to catastrophic accidents in worst cases (Boden, Boden, Peter, Mueller, \& Johnson, 2012; Rebella, 2015). From those elements, we can hypothesize that athletes can execute this phase whit different interindividual engagement which could impact differently the horizontal speed. To date, no study focused on how athletes manage pole-planting task in a high-speed context.

Given that take-off speed is strongly correlated to performance, it is of interest to understand how athletes of both genders deal with pole carriage and how it affects their run-up speed and related spatiotemporal parameters. Additionally, a better understanding of how pole planting preparation influences horizontal speed prior take-off could help coaches to manage training process in order to obtain marginal gain on this crucial performance factor. The aim of this present study was to investigate the respective influence of gender and additional constraint (pole carriage, pole plant preparation, full jump) on running speed and spatiotemporal parameters. We expected an increasing alteration of running speed and related parameters with the increasing constraint. However, due to the lack of available data on women pole vault, we did not have sound expectation related to the gender effect.

\section{Methodology}

\subsection{Experimental approach}

In order the investigate the impact of the pole carriage, pole plant and trial in competition on the spatiotemporal parameters of sprinting, measurements were performed during 2017 National Indoor Championship (Youth and Elite) and during a national pole vault training camp organized by the French Federation of Athletics. Those measurements were performed as a part of athlete's followup from the Federation.

\subsection{Participants}

All athletes involved in this study volunteered to participate in the measurement session during the pole vault training camp. All athletes recruited for this training camp were integrated in selection process to get involved in youth national team; 10 women (age: $21.3 \pm 2.5$ years, size: $1.67 \pm 0.07 \mathrm{~m}$, weight: $57.4 \pm 5.6 \mathrm{~kg})$ with personal best from 3.80 to $4.40 \mathrm{~m}$ and 7 men (age: $20.4 \pm 1.1$ years, height: $1.76 \pm 0.02 \mathrm{~m}$, weight: $68.5 \pm 5.0 \mathrm{~kg})$ with personal 


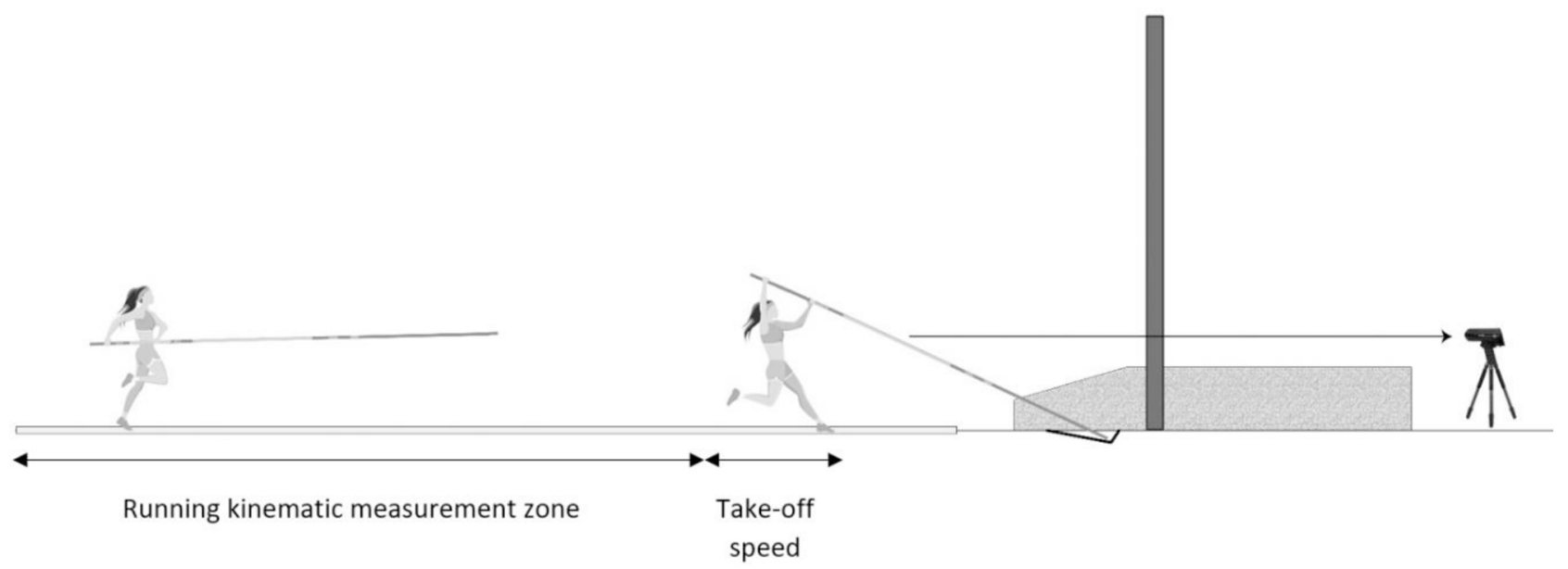

Fig. 1. Experimental set-up used during full jump in competition.

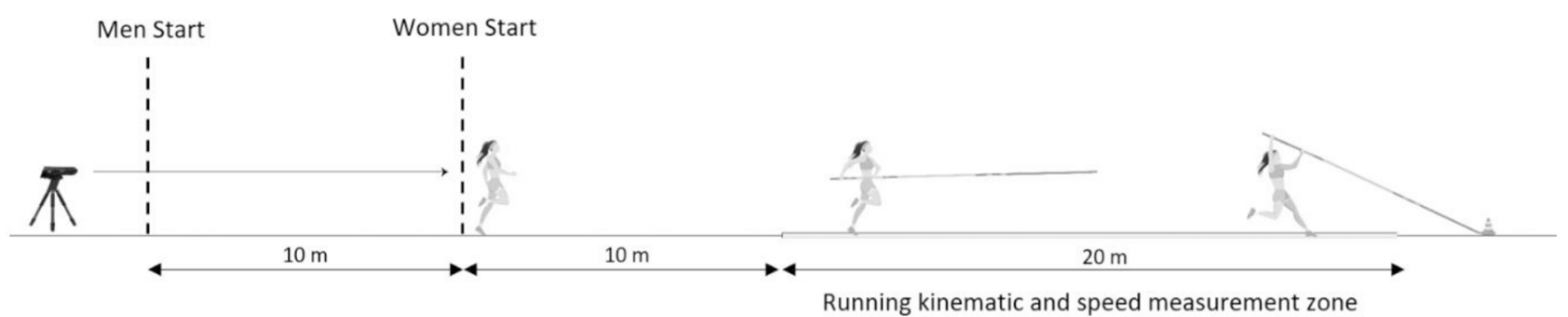

Fig. 2. Experimental set-up used during sprint, sprint with pole carriage and sprint with simulated pole planting.

best from 4.75 to $5.24 \mathrm{~m}$. All of them were free of injury during the measurements period. All athletes were informed about the measurements during the competitions and provided consent to participate. This study was conducted in accordance with the recommendations of the Declaration of Helsinki.

\section{Mechanical measurement}

\subsection{Measurement during competition}

During competition, $20 \mathrm{~m}$ of Optojump Next system (Microgate, Bolzano, Italy) were installed on each side of run-up lane to record the spatiotemporal parameters of the approach run and a radar gun (Stalker Pro II, Stalker ltd, Plano, TX) was positioned behind the landing mat in the run-up direction at a $1.4 \mathrm{~m}$ height to allow direct sight of athletes' torsos along the approach runway (Fig. 1), as previously used (Cassirame, Sanchez, Homo, et al., 2017). The Optojump Next systems provide a direct measurement of contact time on the floor $\left(t_{c}\right)$, aerial time $\left(t_{a}\right)$, step rate (SR) and step length (SL). SL asymmetry $\left(\mathrm{SL}_{\text {asys }}\right)$ was calculated as percentage of difference between left and right length steps. Those parameters were computed from the 3 rd up to 8th last steps of the run-up. The last two steps of the approach were excluded from the analysis to avoid misinterpretation. Those steps are commonly used by athletes to adjust the take-off position and are not representative of the preceding steps of the run-up as previously observed by Makaruk, Porter, Starzak, \& Szymczak (2016). Using synchronization between both devices, speed (Spd) at take-off (TK) was calculated as the average of $0.2 \mathrm{~s}$ before last contact time from speed values input from the radar gun. The radar gun system outputted horizontal speed at a sampling rate of $46.875 \mathrm{~Hz}$ to a computer by RS 232 connection and was integrated into MookyStalker software 2.0.7 (Mtraining, Ecole Valentin, France) to calculate takeoff speed using time information of contact time broadcasted by the Optojump Next system.

\subsection{Measurement during training camp}

During the training camp athletes performed randomly several conditions of sprint: 2 classic sprints, 2 sprints with pole carriage and 2 sprints with pole carriage and pole planting simulation. In the last condition, athletes had to focus on running and planting the pole on a yellow circle marker ( $5 \mathrm{~cm}$ high) to allow locomotor regulation to reach the target. All sprints were performed in the same lane with 8 minutes of recovery between them. All men performed $40 \mathrm{~m}$ sprints whereas women performed $30 \mathrm{~m}$ sprint to be in accordance with typical run-up distance used in competition.

For all those sprints, all the recordings were performed with same configuration than competition situation (Fig. 2). The Optojump Next systems were installed in 
Table 1. Speed and spatiotemporal parameters for Women and Men in different conditions.

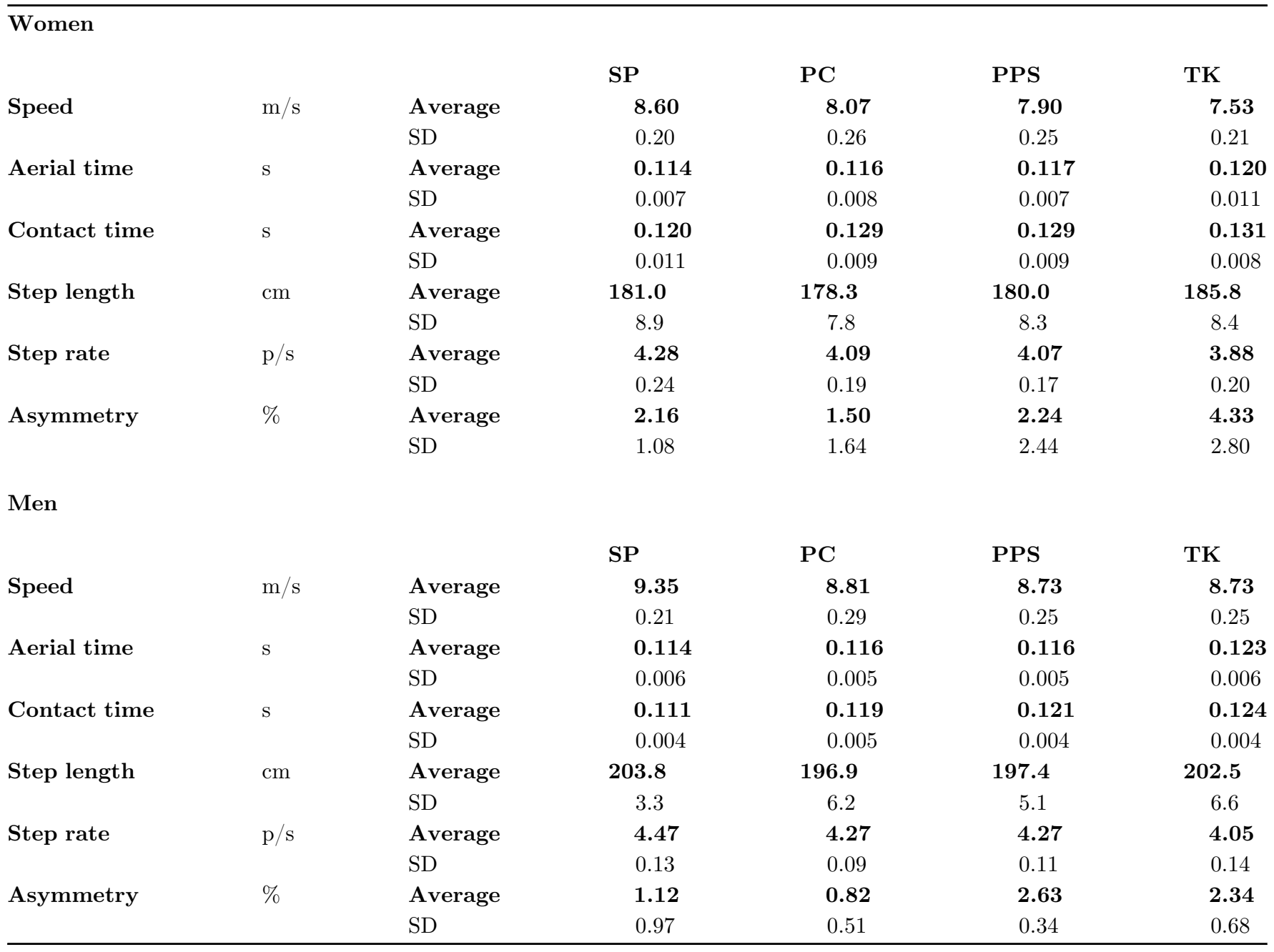

Note: SP: sprint; PC: pole cariage; PPS: pole plant simulated; TK: take-off in official competition.

the last 20 meters of sprint distance (20 to $40 \mathrm{~m}$ for men and 10 to $30 \mathrm{~m}$ for women). In this situation, maximal speed (Spd) was calculated searching the highest rolling average speed on $0.2 \mathrm{~s}$ duration for sprint $(\mathrm{SP})$ and sprint with pole carriage $(\mathrm{PC})$ and as the average of $0.2 \mathrm{~s}$ before last contact time for pole planting simulation (PPS).

\subsection{Statistics}

Descriptive statistics (mean $\pm \mathrm{SD}$ ) are reported for all variables (Spd, $\mathrm{t}_{\mathrm{a}}, \mathrm{t}_{\mathrm{c}}, \mathrm{SL}, \mathrm{SR}, \mathrm{SL}_{\mathrm{asy}}$ ) and both genders and conditions using Microsoft Excel 2013 (Microsoft, Redmond, United-states). The normality of the distributions and homogeneity of the variances were confirmed using Shapiro-Wilk normality tests and the Levene's tests, respectively. Secondly, Two-way ANOVAs (genders, conditions) with repeated measures (conditions) were used to test the main effect of each factor and interaction effect on mechanical variables ( $\mathrm{Spd}, \mathrm{t}_{\mathrm{a}}, \mathrm{t}_{\mathrm{c}}, \mathrm{SL}, \mathrm{SR}, \mathrm{SL}_{\text {asy }}$ ). Pairwise post hoc Tukey's tests were applied to address the effect of sprint condition within each gender. Statistical significance thresholds were set at $\mathrm{P}<0.05^{*}, \mathrm{P}<0.01^{* *}$,
$\mathrm{P}<0.001^{* * *}$ and $\mathrm{P}<0.0001^{* * * *}$. All statistic tests were performed using GraphPad Prism software (GraphPad Software, San Diego, United States).

\section{Results}

All variables measured in those conditions ( $\mathrm{SP}, \mathrm{PC}$, PPS and TK) are reported in Table 1 . A main effect of gender has been found for all the variables $(0.03<\mathrm{P}$ $<0.0001)$ except for $\mathrm{t}_{\mathrm{a}}\left[\mathrm{F}_{(1,15)}<0.001, \mathrm{P}=0.98\right]$ and $\mathrm{SL}_{\text {asy }}$ $\left[\mathrm{F}_{(1,15)}=2.14, \mathrm{P}=0.16\right]$. Among conditions, Spd, SL and $\mathrm{SR}$ were higher for Men than Women, while $t_{c}$ was lower for Men than Women (Fig. 3). A main effect of the conditions has been found for all the variables $(0.0004<$ $\mathrm{P}<0.0001)$. Also, solely Spd presented an interaction effect between genders and conditions $\left[\mathrm{F}_{(3,45)}=12.15\right.$, $\mathrm{P}<0.0001]$. Pairwise post hoc Tukey's tests are presented in Table 2 and Figure 3. Adding further constraints on sprint mechanics led to a progressive decline in Spd for Women, while solely the SP condition had higher Spd values than PC, PPS and TK for Men. This interaction between genders and conditions was confirmed when 

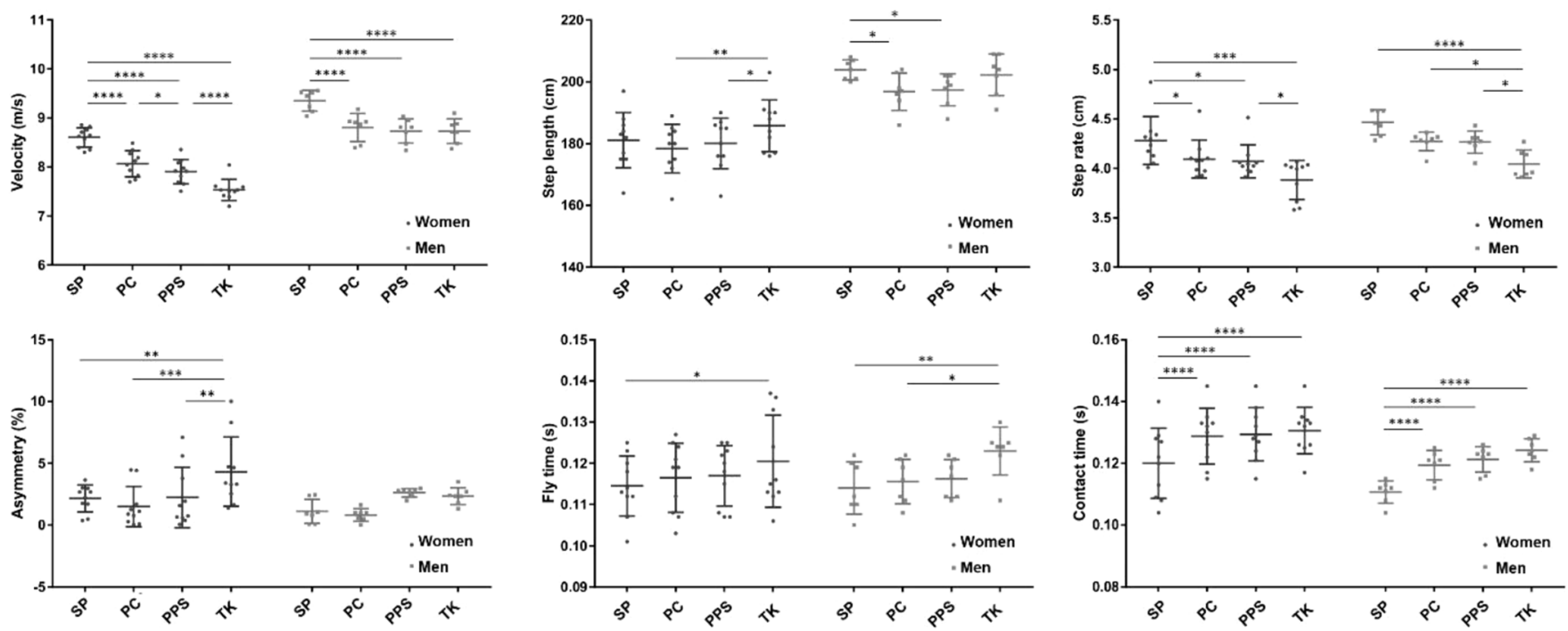

Fig. 3. Mechanical parameters representation by gender and for each condition. SP: sprint; PC: pole cariage; PPS: pole plant simulated; TK: take-off in official competition. Significance of mean difference are represented with $*$ for $\mathrm{P}<0.05, * *$ for $\mathrm{P}<0.01, * * *$ for $\mathrm{P}<0.001$ and $* * * *$ for $\mathrm{P}<0.0001$

normalizing Spd values according to SP condition (Fig. 4), with a significant difference between Men and Women TK only $(\mathrm{P}<0.0001)$. Overall, Table 2 and Figure 3 pointed out a decrease in SR and an increase in $t_{a}$ and $t_{c}$ while adding further constraints on the sprint mechanics. Changes in SL between the conditions revealed a U-shape pattern, with the highest SL values in SP and TK. For $\mathrm{SL}_{\text {asy }}$, a similar trend appeared with $\mathrm{TK}$ condition exhibiting the highest values.

\section{Discussion}

This study aimed at determining the influence of genders and additional constraints (pole carriage, pole plant preparation, full jump) on running speed and spatiotemporal parameters. As expected, we found that adding constraints altered sprinting speed and all the related spatiotemporal parameters for both women and men. Moreover, a gender effect has been found for almost all the studied variables, but solely speed values exhibited an interaction effect between both factors. Taken together, these results showed that both women and men had similar reorganization of their sprint mechanics to cope with the growing external demand (pole carriage, pole plant, take-off). But, these changes had different effects on the resultant speed according to the gender.

Over the sprint conditions, our results showed that men are faster than women thanks to higher values of step length and rate and lower contact time, while aerial time and asymmetry did not differ. Except for speed, the lack of interaction between genders and sprinting conditions suggested that whatever the external demand (here, carrying and planting a pole, or even performing a full trial in competition), the basic mechanics underlying the speed production remained true (Mero et al., 1992; Cassirame, Sanchez, \& Morin, 2017). The lack of gender effect on aerial time disagreed with those from Monte et al. (2017), who experimentally varied the step rate. This discrepancy might come from the low values of aerial times for women in our study (Tab. 1) in comparison with those from this previous study $(0.120-0.137 \mathrm{~s})$. The absence of difference in asymmetry between both genders might imply a specificity of elite pole vaulters to avoid unbalanced running related to the pole carriage.

Between the conditions, aerial and contact time tended to increase while step rate gradually decreased when adding further constraint on the sprint biomechanics (Fig. 3). With regards to the overall decrease in speed due to pole carriage, our results are in line with the study of Monte, Muollo, Nardello, \& Zamparo (2017), which showed increased in aerial and contact times concomitant with the decrease in step rate. Nevertheless, our results suggested some specificities related to pole carriage and/or competition. More specifically, all pole carriage conditions (PC, PPS and TK) decreased step rate and increased contact times in comparison with SP, which was in line with previous studies (Frère et al., 2009; Macadam, Simperingham, \& Cronin, 2019). The competition (TK) further lowered step rate and led to the highest aerial time. These adaptations in competition might be related to a slightly different approach run in comparison to the sprints performed during SP, PC and PPS. Indeed, the athletes tend to progressively increase their running speed and more or less regulate their foot placement to prepare the take-off and perform the full jump (Needham et al., 2017; Frère, Garnier, Sanchez, \& Cassirame, 2019). Therefore, this approach run in competition might lead to specific alteration in step rate and aerial time due to the following take-off and jump actions more than the pole planting movement itself (PC and PPS did not differ in aerial and contact times nor in step rate). 
Table 2. Results of Tukey's multiple comparisons test for all variables. For each gender and between conditions, mean difference (Mean Diff.), 95\% of confidence interval (95\% CI of diff.) and adjusted P-value are displayed.

\begin{tabular}{|c|c|c|c|c|c|c|}
\hline & \multicolumn{3}{|c|}{ Women } & \multicolumn{3}{|c|}{ Men } \\
\hline & Mean Diff. & 95\% CI of diff. & Adj. P-value & Mean Diff. & 95\% CI of diff. & Adj. P-value \\
\hline \multicolumn{7}{|l|}{ Speed } \\
\hline $\mathrm{SP}$ vs. $\mathrm{PC}$ & $0.537 * * * *$ & 0.385 to 0.688 & $<0.0001$ & $0.544 * * * *$ & 0.363 to 0.725 & $<0.0001$ \\
\hline SP vs. PPS & $0.7 * * * *$ & 0.548 to 0.851 & $<0.0001$ & $0.617 * * * *$ & 0.435 to 0.798 & $<0.0001$ \\
\hline $\mathrm{SP}$ vs. TK & $1.072 * * * *$ & 0.920 to 1.223 & $<0.0001$ & $0.618^{* * * *}$ & 0.437 to 0.799 & $<0.0001$ \\
\hline $\mathrm{PC}$ vs. PPS & $0.163^{*}$ & 0.011 to 0.314 & 0.0307 & 0.072 & -0.108 to 0.253 & 0.7095 \\
\hline PC vs. TK & $0.535 * * * *$ & 0.383 to 0.686 & $<0.0001$ & 0.074 & -0.107 to 0.255 & 0.6969 \\
\hline PPS vs. TK & $0.372 * * * *$ & 0.220 to 0.523 & $<0.0001$ & 0.001 & -0.179 to 0.182 & $>0.9999$ \\
\hline \multicolumn{7}{|l|}{ Aerial time } \\
\hline $\mathrm{SP}$ vs. $\mathrm{PC}$ & -0.002 & -0.007 to 0.003 & 0.7810 & -0.002 & -0.008 to 0.005 & 0.9248 \\
\hline $\mathrm{SP}$ vs. $\mathrm{PPS}$ & -0.002 & -0.008 to 0.003 & 0.6418 & -0.002 & -0.009 to 0.004 & 0.8031 \\
\hline $\mathrm{SP}$ vs. TK & $-0.006^{*}$ & -0.011 to -0.001 & 0.0334 & $-0.009 * *$ & -0.02 to -0.002 & 0.0048 \\
\hline $\mathrm{PC}$ vs. PPS & -0.001 & -0.006 to 0.005 & 0.9953 & -0.001 & -0.007 to 0.006 & 0.9920 \\
\hline $\mathrm{PC}$ vs. TK & -0.004 & -0.009 to 0.002 & 0.2469 & $-0.007^{*}$ & -0.014 to -0.001 & 0.0259 \\
\hline PPS vs. TK & -0.003 & -0.009 to 0.002 & 0.3600 & -0.006 & -0.013 to 0.001 & 0.0517 \\
\hline \multicolumn{7}{|c|}{ Contact time } \\
\hline $\mathrm{SP}$ vs. $\mathrm{PC}$ & $-0.009 * * * *$ & -0.012 to -0.005 & $<0.0001$ & $-0.009 * * *$ & -0.014 to -0.004 & 0.0002 \\
\hline $\mathrm{SP}$ vs. PPS & $-0.009 * * * *$ & -0.013 to -0.005 & $<0.0001$ & $-0.010 * * * *$ & -0.016 to -0.006 & $<0.0001$ \\
\hline $\mathrm{SP}$ vs. TK & $-0.01 * * * *$ & -0.014 to -0.006 & $<0.0001$ & $-0.014 * * * *$ & -0.018 to -0.009 & $<0.0001$ \\
\hline $\mathrm{PC}$ vs. PPS & -0.001 & -0.004 to 0.003 & 0.9806 & -0.0019 & -0.007 to 0.003 & 0.7545 \\
\hline $\mathrm{PC}$ vs. TK & -0.0018 & -0.005 to 0.002 & 0.6612 & -0.005 & -0.009 to 0.001 & 0.0592 \\
\hline PPS vs. TK & -0.001 & -0.005 to 0.003 & 0.8691 & -0.003 & -0.008 to 0.002 & 0.3873 \\
\hline \multicolumn{7}{|l|}{ Step length } \\
\hline $\mathrm{SP}$ vs. $\mathrm{PC}$ & 2.7 & -2.215 to 7.615 & 0.4663 & $7 *$ & 1.126 to 12.87 & 0.0137 \\
\hline $\mathrm{SP}$ vs. $\mathrm{PPS}$ & 1 & -3.915 to 5.915 & 0.9480 & $6.429 *$ & 0.5545 to 12.3 & 0.0270 \\
\hline $\mathrm{SP}$ vs. TK & -4.7 & -9.615 to 0.214 & 0.0655 & 1.571 & -4.303 to 7.445 & 0.8912 \\
\hline PC vs. PPS & -1.7 & -6.615 to 3.215 & 0.7928 & -0.571 & -6.445 to 5.303 & 0.9938 \\
\hline $\mathrm{PC}$ vs. TK & $-7.4^{* *}$ & -12.31 to -2.485 & 0.0012 & -5.429 & -11.3 to 0.4455 & 0.0794 \\
\hline PPS vs. TK & $-5.7^{*}$ & -10.61 to -0.785 & 0.0172 & -4.857 & -10.73 to 1.017 & 0.1372 \\
\hline \multicolumn{7}{|l|}{ Step rate } \\
\hline $\mathrm{SP}$ vs. $\mathrm{PC}$ & $0.186^{*}$ & 0.012 to 0.361 & 0.0321 & 0.191 & -0.017 to 0.399 & 0.0829 \\
\hline $\mathrm{SP}$ vs. $\mathrm{PPS}$ & $0.208^{*}$ & 0.034 to 0.383 & 0.0133 & 0.198 & -0.009 to 0.407 & 0.0667 \\
\hline $\mathrm{SP}$ vs. TK & $0.396 * * *$ & 0.222 to 0.571 & $<0.0001$ & $0.419 * * * *$ & 0.211 to 0.628 & $<0.0001$ \\
\hline PC vs. PPS & 0.022 & -0.152 to 0.196 & 0.9863 & 0.007 & -0.201 to 0.216 & 0.9997 \\
\hline PC vs. TK & $0.210^{*}$ & 0.035 to 0.384 & 0.0125 & $0.229 *$ & 0.020 to 0.437 & 0.0265 \\
\hline PPS vs. TK & $0.188^{*}$ & 0.013 to 0.362 & 0.0302 & $0.221 *$ & 0.012 to 0.429 & 0.0338 \\
\hline \multicolumn{7}{|l|}{ Asymmetry } \\
\hline $\mathrm{SP}$ vs. $\mathrm{PC}$ & 0.655 & 0.012 to 0.361 & 0.7290 & 0.300 & -0.017 to 0.399 & 0.9784 \\
\hline SP vs. PPS & -0.083 & 0.034 to 0.383 & 0.9992 & -1.507 & -0.009 to 0.407 & 0.2051 \\
\hline $\mathrm{SP}$ vs. TK & $-2.168 * *$ & 0.222 to 0.571 & 0.0069 & -1.224 & 0.211 to 0.628 & 0.3773 \\
\hline PC vs. PPS & -0.738 & -0.152 to 0.197 & 0.6490 & -1.807 & -0.200 to 0.216 & 0.0931 \\
\hline $\mathrm{PC}$ vs. TK & $-2.823 * * *$ & 0.036 to 0.385 & 0.0003 & -1.525 & 0.020 to 0.437 & 0.1964 \\
\hline PPS vs. TK & $-2.084^{* *}$ & 0.013 to 0.362 & 0.0100 & 0.282 & 0.012 to 0.429 & 0.9820 \\
\hline
\end{tabular}

Note: SP: sprint; PC: pole cariage; PPS: pole plant simulated; TK: take-off in official competition. Significance of mean difference are represented with * for $\mathrm{P}<0.05$, ** for $\mathrm{P}<0.01$, *** for $\mathrm{P}<0.001$ and $* * * *$ for $\mathrm{P}<0.0001$. 


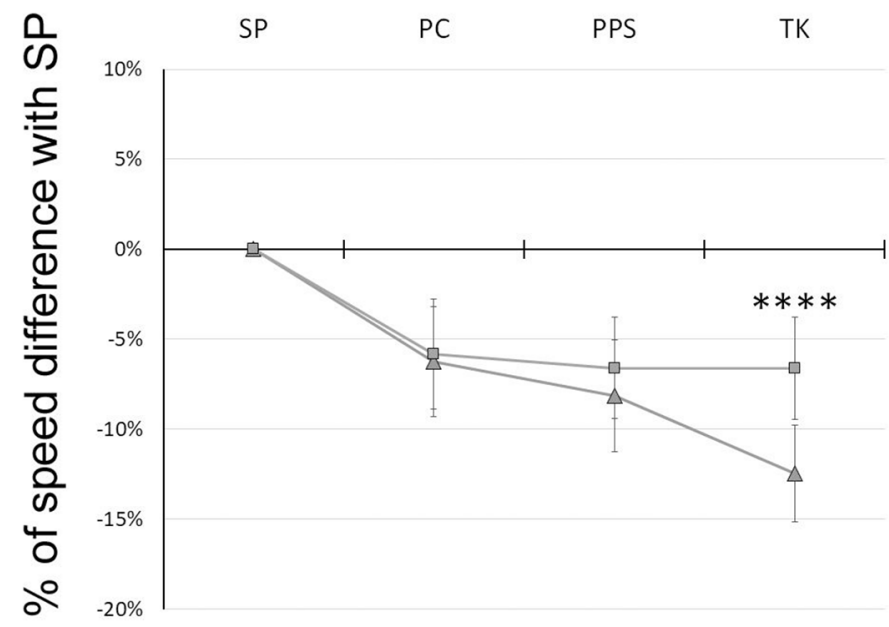

Fig. 4. Speed reduction compared with sprint condition. PC: pole cariage; PPS: pole planting simulation; TK: take-off during official competition. $\square$ : men and $\boldsymbol{\Delta}$ : women. Significance of mean difference are represented with $*$ for $\mathrm{P}<0.05$, ** for $\mathrm{P}<0.01, * * *$ for $\mathrm{P}<0.001$ and $* * * *$ for $\mathrm{P}<0.0001$.

Changes in asymmetry and step length between the conditions also seemed affected by the specificity of the approach run in competition. Asymmetry in step length was the highest in competition and tended to be the lowest in pole carriage only (PC). Overall, these results confirmed the ability of elite pole vaulter to cope efficiently with the unbalanced related to pole carriage, but adding further constraints (PPS and TK) led to a progressive increase in asymmetry. However, these changes in asymmetry did not seem to be at the expense of the speed changes between the conditions and even less of performance (Cassirame et al., 2019). As found in previous studies, pole carriage and more generally extra-weight or arm swing restriction decreased the step length (Frère et al., 2009; Cross, Brughelli, \& Cronin, 2014; Macadam, Cronin, \& Feser, 2019). However, one can note that during competition, step length reached similar level than in SP condition. This increase in step length, in relationship with the increase in aerial time, might be seen as a strategy to cope with the decline in step rate into an attempt to maintain or limiting the decrease in speed. And this strategy seemed to be effective for men and not enough for women, as they gradually loss speed across conditions.

We observed a significant speed reduction when a pole is carried (SP vs. PC) for both Women and Men $(-6.2 \%$ and $-5.8 \%$, respectively). This finding was in line with results of Frère et al. (2009) who observed a $6.6 \%$ decrease in speed. The speed reduction shown with pole carriage was also demonstrated for both female and male in PPS $(-8.1 \%$ and $-6.6 \%$, respectively) and but in TK, speed loss continued for women, while plateaued for men (respectively $-12.4 \%$ and $-6.6 \%$; Fig. 4 ). Several mechanisms have been previously proposed to explain this speed alteration as additional load of the pole (around $2 \mathrm{~kg}$ ) and restricted arm swing due to pole carriage. Running with additional weight led to maximal speed reduction proportionally to the load applied (Cross, Brughelli, \& Cronin, 2014; Macadam, Cronin, et al., 2019) and placement of this extra-weight (Cross et al., 2014; Macadam, Cronin et al., 2019; Ropret, Kukolj, Ugarkovic, Matavulj, \& Jaric, 1998). Ropret et al. (1998) reported only a small decrease of speed with arm load $(0.66 \mathrm{~kg})$ (Ropret et al., 1998), while Macadam, Simperingham, et al. (2019) observed significant decrease in $20 \mathrm{~m}$ sprint time with forearms wearable load of $1 \mathrm{~kg}$ (each) for young male athletes (Macadam, Simperingham, et al., 2019). Our results (SP vs. PC) agreed with this last study reporting similar contact time increase and step rate decrease, except that they found small step length increase with forearms load. This discrepancy in step length changes might be due to the fact that forearm load increases inertia during running and does not restrict arms movements as in pole carriage. Arm restriction was also pointed out to explain speed decrease in PC condition (Frère et al., 2009). During running, arm movements are crucial to control and maintain posture and participate (nearly 10\%) to total vertical propulsive forces (Macadam, Cronin, Uthoff, Johnston, \& Knicker, 2018). A lack of arm-leg coordination related to pole carriage might reduce the forces applied in running and alter postural control strategy with higher implication of the lower limbs and trunk. These modifications could mainly be responsible of speed decrease, as found in the context of ball carriage (Grant et al., 2003).

Solely speed presented an interaction effect between both gender and conditions. More specifically, speed loss in men plateaued among the three conditions with pole carriage, while women showed a progressive decrease in speed with the growing external demand (PC, PPS and then TK). Take-off speed is a crucial parameter for pole vault and has been reported as a biggest determinant of performance in many studies (Cassirame, Sanchez, Homo, et al., 2017; Frère, 2009; Steinacker, 1991). These findings related to changes in speed according to both genders and conditions might be of high interest for coaches. Due to methodological considerations, we can state that speed decrease observed for women was probably localized in the last 2 steps of the run-up with massive adjustment of running pattern before the planting pole and the take-off. Indeed, steps parameters in competition were calculated from 6 steps from n- 8 to n- 2 , while speed was measured during last $0.2 \mathrm{~s}$ before last contact time (see methods). Moreover, similar speed reduction was previously reported in young women athletes whereas men did not decrease their speed before take-off (Cassirame \& Sanchez, 2015). To date, no clear information can be provided to explain causes of this speed alteration for women athletes. The first speculative hypothesis could be that women have more difficulties for lowering the pole in the last 2 steps to plant the pole in the box due to their muscular capabilities which are lesser than men. This highly technical movement required many motors control skills and power due to the torque induced by pole length. Women could be more affected by this action and could lost more speed during this phase. A second speculative hypothesis could 
consider psychological aspect. Pole vault is a relatively dangerous activity where take-off phase induces important impact on musculoskeletal system and may cause damage or accident (Rebella, 2015). We can suppose that women decrease significantly their speed to protect themselves from more important impact at take-off. Several studies pointed out that men take more risks than women to preserve themselves more from danger (Harris \& Jenkins, 2006; Pawlowski, Atwal, \& Dunbar, 2008). Men can also take the advantage from their muscular apparatus and possibly form a more effective take-off pole angle (with higher upper hand) decreasing the potential side effect of an impact.

\section{Brief perspective}

This study highlight causes and magnitudes of velocity decrement related to pole carriage during the run-up phase for both female and male. Those findings permit to get a clearer interpretation of this effect highly detrimental for performance (Cassirame, Sanchez, Homo, et al., 2017; Frère et al., 2010). Nevertheless, further investigations are needed to verify if this speed decline could be also observed in female world-class athlete and to understand the underlying mechanisms involved in speed decrement for female in order to find appropriated training programmes. The causes could be multiple, mixing technical or psychological issues such as take-off pattern, pole stiffness, accident history and many others that result in unconscious stress leading to speed reduction mechanisms. Finally, those results can permit coaches to focus their training exercises aiming to eliminate speed decrement in entire jump situation.

\section{Limitation}

For convenience, sprint exercises were performed during training whereas pole vault take-off speeds were measured during an official competition. Competition could have significant positive effect on take-off speed as described by Christensen \& Zebas (2000).

\section{Conclusion}

Speed acquired during run-up in pole vault is the main source of energy. Pole carriage, pole planting preparation and take-off apprehension may cause significant decrease in speed when compared with maximum capabilities of athletes. For young elite athletes, pole carriage leads to the highest speed decrease for both male $(-5.8 \%)$ and female $(-6.2 \%)$. During pole carriage, step rate and length decrease were pointed out with an increase of contact time. In addition, take-off induces an additional significant speed reduction for female only $(-4.3 \%)$. To date, mechanisms involved in this phenomenon are not clear and required more investigations. A better understanding could remediate this issue by providing exercises or technical advice.
Acknowledgment. Authors want to thank all athletes who participated in this study and coach involved in measurement session during the training camp. This work was supported by the French Ministry of Sport and the French Institute of Sport under Grant 16-R-14, and the French Athletics Federation.

\section{Conflict of interest}

The authors declare that they have no conflicts of interest in relation to this article.

\section{References}

Abe, T., Dankel, S.J., Buckner, S.L., Jessee, M.B., Mattocks, K.T., Mouser, J.G., Bell, Z.W., Loenneke, J.P. (2019). Differences in 100-m sprint performance and skeletal muscle mass between elite male and female sprinters. The Journal of Sports Medicine and Physical Fitness, 59(2), 304-309. https://doi.org/10.23736/S0022-4707.18.08267-1.

Arampatzis, A., Schade, F., \& Brüggemann, G.P. (2002). Interaction between the pole and the human body and its effect on the pole vaulting performance. ISBS-Conference Proceedings Archive, 1(1). Consulté à l'adresse https://ojs. ub.uni-konstanz.de/cpa/article/view/706.

Boden, B.P., Boden, M.G., Peter, R.G., Mueller, F.O., \& Johnson, J.E. (2012). Catastrophic injuries in pole vaulters: A prospective 9-year follow-up study. The American Journal of Sports Medicine, 40(7), 1488-1494. https://doi.org/ $10.1177 / 0363546512446682$.

Bushnell, T., \& Hunter, I. (2007). Differences in technique between sprinters and distance runners at equal and maximal speeds. Sports Biomechanics, 6(3), 261-268. https://doi.org/ 10.1080/14763140701489728.

Cassirame, J., \& Sanchez, H. (2015). Comparaison des paramètres de la performance chez les perchistes en fonction du sexe et de la catégorie. $16^{e}$ congrès de l'ACAPS, 1 . Nantes: ACAPS.

Cassirame, J., Sanchez, H., Homo, S., \& Frère, J. (2017). Mechanical performance determinants in women's vs. men's pole-vault. Computer Methods in Biomechanics and Biomedical Engineering, 20(sup1), 37-38. https://doi.org/10.1080/ 10255842.2017.1382849.

Cassirame, J., Sanchez, H., \& Morin, J.B. (2017). The elevated track in pole vault: an advantage during run-up? International Journal of Sports Physiology and Performance, 1-22. https://doi.org/10.1123/ijspp.2016-0724.

Cassirame, J., Sanchez, H., Exell, T.A., Panoutsakopoulos, V., Theodorou, A.S., Homo, S., \& Frère, J. (2019). Differences in approach run kinematics: Successful vs. unsuccessful jumps in the pole vault. International Journal of Performance Analysis in Sport, 19(5), 794-808. https://doi.org/10.1080/ 24748668.2019.1657655.

Choi, K.-J., Yi, K.-O., Kim, N.-H., Kang, J.-E., Kim, H.-L., Moon, J.-H., \& Jung, B.-C. (2013). Comparative analyses on kinematic variables of women's pole vault competition at IAAF World Championships Daegu 2011. Korean Journal of Sport Biomechanics, 23(3), 189-200.

Christensen, B., \& Zebas, C. (2000). A comparison of practice and competition approach velocities and the position of the top handhold at the pole plant in pole vaulters. ISBS Conference Proceedings Archive, 1(1). Consulté à l'adresse https://ojs.ub.uni-konstanz.de/cpa/article/view/2375. 
Cross, M.R., Brughelli, M.E., \& Cronin, J.B. (2014). Effects of vest loading on sprint kinetics and kinematics. Journal of Strength and Conditioning Research, 28(7), 1867-1874. https://doi.org/10.1519/JSC.0000000000000354.

Decker, A., \& Bird, M. (2008). Predicting potential jump height in the pole vault from four variables. ISBS-Conference Proceedings Archive, 1(1). Consulté à l'adresse https://ojs. ub.uni-konstanz.de/cpa/article/view/1291.

Ekevad, M., \& Lundberg, B. (1997). Influence of pole length and stiffness on the energy conversion in pole-vaulting. Journal of Biomechanics, 30(3), 259-264.

Frère, J. (2009). Contribution de l'analyse électromyographique des muscles des membres supérieurs pour l'entraînement au saut à la perche. Université de Rouen. Consulté à l'adresse https://tel.archives-ouvertes.fr/tel-00590379/.

Frère, J., Chollet, D., \& Tourny-Chollet, C. (2009). Assessment of the influence of pole carriage on sprint kinematics: A case study of novice athletes. International Journal of Sports Science and Engineering, 3(1), 3-10.

Frère, J., L'hermette, M., Slawinski, J., \& Tourny-Chollet, C. (2010). Mechanics of pole vaulting: A review. Sports Biomechanics/International Society of Biomechanics in Sports, 9(2), 123-138. https://doi.org/10.1080/14763141.2010.492430.

Frère, J., Göpfert, B., Hug, F., Slawinski, J., \& Tourny-Chollet, C. (2012). Catapult effect in pole vaulting: Is muscle coordination determinant? Journal of Electromyography and Kinesiology, 22(1), 145-152.

Frère, J., Sanchez, H., Homo, S., Rabita, G., Morin, J.B., \& Cassirame, J. (2017). Influence of pole carriage on sprint mechanical properties during pole vault run-up. Computer Methods in Biomechanics and Biomedical Engineering, 20 (sup1), 83-84. https://doi.org/10.1080/10255842.2017.1382872.

Frère, J., Garnier, A., Sanchez, H., \& Cassirame, J. (2019). The pattern of locomotor regulation during the approach run has no influence on the effectiveness of the following phases for male pole vaulters. Computer Methods in Biomechanics and Biomedical Engineering, 22, S335-S336. https://doi.org/ 10.1080/10255842.2020.1714930.

Grant, S.J., Oommen, G., McColl, G., Taylor, J., Watkins, L., Friel, N., Watt, I., \& McLean, D. 2003. The effect of ball carrying method on sprint speed in rugby union football players. Journal of Sports Sciences, 21(12), 1009-1015. https://doi.org/10.1080/0264041031000140671.

Harris C.R., \& Jenkins, M. (2006). Gender differences in risk assessment: Why do women take fewer risks than men? Judgment and Decision Making, 1(1), 49-63.

Linthorne, N.P., \& Weetman, A.H.G. (2012). Effects of run-up velocity on performance, kinematics, and energy exchanges in the pole vault. Journal of Sports Science $\&$ Medicine, 11(2), $245-254$.

Macadam, P., Cronin, J.B., Uthoff, A.M., Johnston, M., \& Knicker, A.J. (2018). Role of arm mechanics during sprint running: A review of the literature and practical applications. Strength $\&$ Conditioning Journal, 40(5), 14. https://doi.org/ 10.1519/SSC0000000000000391.

Macadam, P., Simperingham, K.D., \& Cronin, J.B. (2019). Forearm wearable resistance effects on sprint kinematics and kinetics. Journal of Science and Medicine in Sport, 22(3), 348-352. https://doi.org/10.1016/j.jsams.2018.08.012.
Macadam, P., Cronin, J.B., \& Feser, E.H. (2019). Acute and longitudinal effects of weighted vest training on sprint-running performance: A systematic review. Sports Biomechanics, 1-16. https://doi.org/10.1080/14763141.2019.1607542.

Makaruk, H., Porter, M., Starzak, M., \& Szymczak, E. (2016). An examination of approach run kinematics in track and field jumping events. Polish Journal of Sport and Tourism, 23(2), 82-87. https://doi.org/10.1515/pjst-2016-0009.

Mero, A., Komi, P.V., \& Gregor, R.J. (1992). Biomechanics of sprint running. A review. Sports Medicine (Auckland, N.Z.), 13(6), 376-392.

Monte, A., Muollo, V., Nardello, F., \& Zamparo, P. (2017). Sprint running: How changes in step frequency affect running mechanics and leg spring behaviour at maximal speed. Journal of Sports Sciences, 35(4), 339-345. https://doi. org/10.1080/02640414.2016.1164336.

Needham, L., Exell, T.A., Bezodis, I.N., \& Irwin, G. (2017). Patterns of locomotor regulation during the pole vault approach phase. Journal of Sports Sciences, 0(0), 1-7. https://doi.org/10.1080/02640414.2017.1412236.

Pawlowski, B., Atwal, R., \& Dunbar, R.I.M. (2008). Sex differences in everyday risk-taking behavior in humans. Evolutionary Psychology, 6(1), 147470490800600100. https://doi.org/10.1177/147470490800600104.

Perez-Gomez, J., Rodriguez, G.V., Ara, I., Olmedillas, H., Chavarren, J., González-Henriquez, J.J., Dorado, C., Calbet, J.A.L. (2008). Role of muscle mass on sprint performance: Gender differences? European Journal of Applied Physiology, 102(6), 685-694. https://doi.org/ 10.1007/s00421-007-0648-8.

Rebella, G. (2015). A prospective study of injury patterns in collegiate pole vaulters. The American Journal of Sports Medicine, 43(4), 808-815. https://doi.org/10.1177/ 0363546514564542 .

Ropret, R., Kukolj, M., Ugarkovic, D., Matavulj, D., \& Jaric, S. (1998). Effects of arm and leg loading on sprint performance. European Journal of Applied Physiology and Occupational Physiology, $77(6), \quad 547-550 . \quad$ https://doi.org/10.1007/ s004210050374.

Schade, F., \& Arampatzis, A. (2012). Influence of pole plant time on the performance of a special jump and plant exercise in the pole vault. Journal of Biomechanics, 45(9), 1625-1631. https://doi.org/10.1016/j.jbiomech.2012.03.031.

Schade, F., Arampatzis, A., Brüggemann, G.-P., \& Komi, P. (2004). Comparison of the men's and the women's pole vault at the 2000 Sydney Olympic Games. Journal of Sports Sciences, 22(9), 835-842. https://doi.org/10.1080/ 02640410410001675315.

Schade, F., Arampatzis, A., \& Brüggemann, G.-P. (2006). Reproducibility of energy parameters in the pole vault. Journal of Biomechanics, 39(8), 1464-1471. https://doi.org/ 10.1016/j.jbiomech.2005.03.027.

Steinacker, U. (1991). The run-up speed in the pole vault. Modern Athlete and Coach, 29(2), 14-16.

Theodorou, A., Panoutsakopoulos, V., \& Exell, T. (2016). Step characteristic interaction and asymmetry during the approach phase in pole vault. Journal of Sports Sciences.

Cite this article as: Cassirame J, Sanchez H, Homo S, \& Frère J (2022) Effect of gender, carrying and planting the pole on approach step parameters in young pole vaulters. Mov Sport Sci/Sci Mot, https://doi.org/10.1051/sm/2021019 